\title{
Structure and Property of Hydroperoxide in Solution*
}

\author{
by Shin'ichi Kato**, Takamasa Ishihara** and Fujio Mashio**
}

\begin{abstract}
Summary: Structure and property of hydroperoxide in solution were studied in connection with the epoxidation of olefins. The $p K a$ values of $n-$, sec-and tert-butyl hydroperoxide and that of benzyl-, ethylbenzene- and cumene-hydroperoxide were measured by UV spectrophotometric method and the $p K a$ values were plotted against Taft polor substituent constants. A linear relation was obtained and $\rho^{*}$ value was +4.1 for the aliphatic series, but the line for aromatic series was different from that for aliphatic series even though having almost the same slope. In the case of aromatic hydroperoxides, intramolecular $\pi-H$ bonding between peroxy $H$ and $\pi$-electron of aromatic ring was observed by IR spectrum and the fact well explains why a different line from that of aliphatic series is obtained. The abilities of association and solvation of six hydroperoxides examined in this study were evaluated in terms of the shift of $\nu_{\mathrm{OH}}$ and the relation with $p K a$ is discussed. Equilibrium constants of the dimeric association and the intra molecular $\pi-H$ bonding of hydroperoxide is also estimated. The rates of epoxidation of 1-octene by the six hydroperoxides were measured in the presence of a solvent-soluble molybdenum catalyst and a possible configuration of the transition state complex is suggested.
\end{abstract}

\section{Introduction}

In the case of epoxidation of olefin by hydroperoxide as a source of electrophilic oxygen ${ }^{1)}$, the rate is slow and the yield is low when catalyst is not used ${ }^{2}$. The authors ${ }^{3}$ ) reported previously that the reaction proceeds in the presence of $\mathrm{MoO}_{3}$ at an adequate rate and an epoxide is selectively obtained. The following scheme was proposed in the previous paper.

$$
\begin{aligned}
& \text { ROOH }+ \text { Catalyst } \stackrel{\stackrel{K}{\rightleftarrows}[\text { Complex }]}{\rightleftarrows} \\
& \text { [Complex }]+>\mathrm{C}=\mathrm{C}<\stackrel{k_{2}}{\rightarrow} \\
& >\mathrm{C}-\mathrm{C}<+\mathrm{ROH}+\text { Catalyst }
\end{aligned}
$$

Sheng et al. ${ }^{4}$ studied the effect of catalysts, solvents, reaction temperatures and olefin structure on the epoxidation, and assumed almost the same scheme, but the structure of complex is somewhat different (see below).

Hydroperoxides have a nature of association with each other and with solvent (solvation). The rate of epoxidation is slown down by $\mathrm{H}$ bonding solvation as in the case of peracids. Acidity constants, $\mathrm{pKa}$, of three aliphatic hydroperoxides ( $n$-, sec- and tert-butyl hydroperoxide) and three aromatic hydroperoxides (benzyl-, ethylbenzene- and cumene-hydroperoxide) were measured and the degrees of solvation, and as-

* Received December 8, 1969.

** Kyoto Technical University (Matsugasaki, Sakyo-ku, Kyoto) sociation, especially H-bonding characteristic of the hydroperoxides, were also measured. The interrelation among these values and the reactivities of hydroperoxides in epoxidation are discussed.

\section{Experiments}

\subsection{Materials}

Normal-butyl, sec-butyl and benzyl hydroperoxide were prepared by autoxidation of the corresponding alkyl or benzyl cadmium chloride at $-70 \sim-80^{\circ} \mathrm{C}^{6}$. Ethylbenzene hydroperoxide was prepared by autoxidation of ethylbenzene. Tertiary-butyl and cumene hydroperoxide were obtained from commercial scurces. Each hydroperoxide was purified by the following procedure: the sodium salt was washed with alcohol thoroughly, being dissolved in water and the aqueous solution was acidified with acetic acid and extracted with ether. The ethereal layer was dried over anhydrous sodium sulfate and ether was evaporated in vacuum. The purity was above $97 \%$ by iodmetric titration.

Preparation of Soluble Molybdenum Catalyst:

Permolybdic acid (PMA)- Five percent $(w / v)$ of molybdenum trioxide were added to aqueous $0.2 \mathrm{M} \mathrm{H}_{2} \mathrm{O}_{2}$ solution and the mixture was stirred for ' $10 \mathrm{hrs}$, at $50^{\circ} \mathrm{C}$. About $0.1 \mathrm{M}$ solution of permolybdic acid solution (yellow) was obtained by removing the residual insoluble $\mathrm{MoO}_{3}$. The $10^{-3} \sim 10^{-4} \mathrm{M}$ solution diluted by tert-butanol was an effective homogeneous catalyst for epoxi-

Volume 12-May 1970 
dation.

Diethoxymolybdenyl Chloride (DEM) :

Molybdenum oxychloride $\mathrm{Mo}_{2} \mathrm{O}_{3} \mathrm{Cl}_{6}{ }^{8}$ ) was obtained by heating the mixture of hydrated sodium molybdate $\left(\mathrm{Na}_{2} \mathrm{MoO}_{4} 2 \mathrm{H}_{2} \mathrm{O}\right)$ and an excess thionylchloride. Four equivalent amounts of sodium ethylate in alcohol was added to the oxychloride and diethoxymolybdenum oxychloride assumed to have the following composition $\left(\mathrm{Mo}_{2}\right.$ $\mathrm{O}_{3} \mathrm{Cl}_{2}(\mathrm{OEt})_{4}$, Mo: $39.4^{\circ}$, $\mathrm{Cl}: \quad 15.1 \%$ ) was obtained. The $10^{-3} \sim 10^{-4} \mathrm{M}$ solution of the Mo-salt in tert-butanol is also an effective catalyst.

\subsection{Experimental Methods}

The $\mathrm{pKa}$ value of hydroperoxides was measured by the UV spectrophotometric method"). The conditions of measurement are as shown below: [HP] is $10^{-3} \mathrm{M}$, the ionic strength 0.45 and the reaction temperature is $20 \pm 0.5 \mathrm{C}$ in the system $\mathrm{HP}-\mathrm{KOH}-\mathrm{KCl}$. The key band is $260 \mathrm{~m} \mu$ in aliphatic hydroperoxide and $280 \mathrm{~m} \mu$ in aromatic hydroperoxide. Hitachi double beam UV spectrophotometer type 124 was used. Stretching vibration band of free $\mathrm{OH}$ ( $\nu_{\mathrm{OH}}, \mathrm{free}_{\mathrm{r}}$ ) and associated $\mathrm{OH}$ ( ${ }^{\circ} \mathrm{OH}$, assoc.) were measured in $3 \mu$ region of the IR spectrum. The product of hydroperoxide concentration and the length of light path was set up to be constant by using a convertible $\mathrm{NaCl}$ cell. IR spectra measurements were performed on a Nippon Bunko IR spectrophotometer model DS-402G.

\section{Results and Discussion}

\subsection{Dissociation Constant of HP}

Some $\mathrm{pKa}$ values of hydroperoxides are reported by Everett ${ }^{10}$, but $\mathrm{pKa}$ values of hydroperoxides used in this study are not known. The data determined are shown in Table 1 .

Table 1 The $\mathrm{pKa}$ values of $\mathrm{HP}$

\begin{tabular}{ccccccc}
\hline HPa) & $n-\mathrm{BuHP}$ & $s e c-\mathrm{BuHP}$ & $t e r t$-BuHP & BHP & EHP & CHP \\
$\mathrm{pKa}$ & 12.0 & 12.4 & 12.8 & 11.8 & 12.2 & 12.6 \\
\hline
\end{tabular}

Temperature: $20 \pm 0.5 \mathrm{C}$, Ionic strengh: 0.45

a) BHP: Benzyl Hydroperoxide

EHP: Ethylbenzene Hydroperoxide

CHP: Cumene Hydroperoxide

The $\mathrm{pKa}$ value of hydroperoxide increases in the order of primary, secondary and tertiary in both aliphatic and aromatic series. In order to examine the substituent effect on the acidity of HP, pKa values were plotted against Taft polar substituent constants in Fig. 1. The pKa values of methyl and ethyl hydroperoxide of Everett ${ }^{10)}$

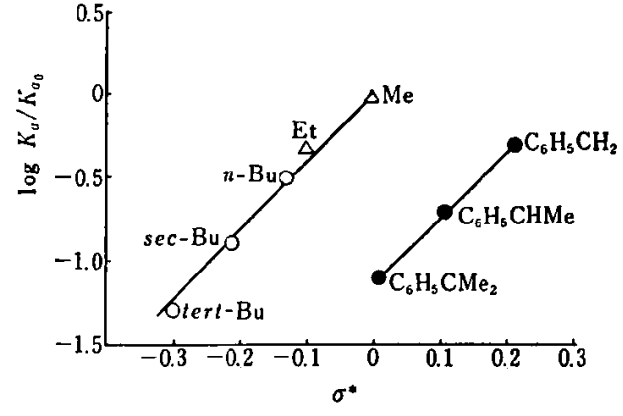

Fig. I Plot. of Ionization Constants of HP and Taft $\sigma^{*}$

were used. Linear relation of Taft equation (3) holds good for the aliphatic series, and $\rho^{*}=$ $+4.1(r=0.913)$ was obtained.

$$
\log K / K_{0}=\rho^{*} \sigma^{*}
$$

This shows that the dissociation constant $\mathrm{Ka}$ (Eq. 4) is governed by I-Effect of substituent R.

$$
\mathrm{ROOH} \stackrel{\stackrel{K a}{\longrightarrow}}{\longrightarrow} \mathrm{ROO}^{-}+\mathrm{H}^{+}
$$

The relation for the aromatic series is different, but the slope is almost the same, and a particular association of aromatic hydroperoxide is suggested. In the following section, an intramolecular $\pi-\mathrm{H}$ bonding between undissociated peroxyhydrogen and aromatic ring, is shown by IR spectrum. The $\rho^{*}$ value of +4.1 is larger than $\rho^{*}(+1.721$ at $\left.25^{\circ} \mathrm{C}\right)^{11)}$ for the aliphatic carboxylic acid and this fact shows that $-\mathrm{O}-$ is much larger than $-\mathrm{C}_{\text {- }}$ in the transmission of I-Effect to the terminal hydrogen.

\subsection{Intra- and Intermolecular Hydrogen Bond of Hydroperoxide}

IR spectra in $3 \mu$ region are shown in Fig. 2 and Fig. 3. The maximum frequency of free $\mathrm{OH}\left(\nu_{\mathrm{OH}}, \mathrm{f}_{\mathrm{ree}}\right)$ is at $3,553 \mathrm{~cm}^{-1}$ in the case of Fig. 2-A. The relative intensity of $v_{\mathrm{OH}}$, free and

$$
\text { tert-BuHP in } \mathrm{CCl}_{4}, 22 \pm 1^{\circ} \mathrm{C} \quad \mathrm{CHP} \text { in } \mathrm{CCl}_{4}, 22 \pm 1^{\circ} \mathrm{C}
$$

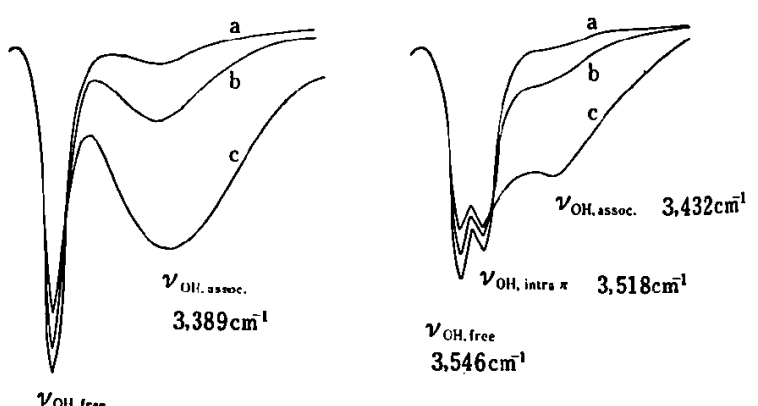

$3.553 \mathrm{~cm}^{-1}$

$$
\begin{aligned}
& \text { a. } \mathrm{HP}=0.012 \mathrm{M} \\
& \text { b. } \mathrm{HP}=0.06 \mathrm{M} \\
& \text { c. } \mathrm{IIP}=0.24 \mathrm{M}
\end{aligned}
$$

Fig. 2-A 

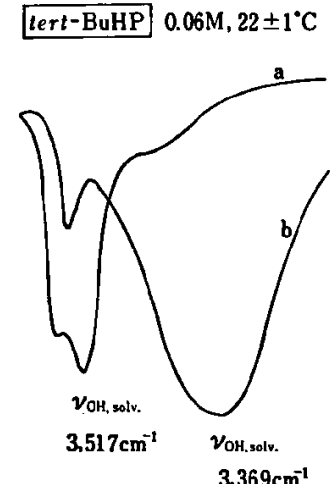

a. in $\mathrm{C}_{6} \mathrm{H}_{6}+\mathrm{CCl}_{4}(1: 1)$

b. in Dioxane $+\mathrm{CCl}_{1}(1: 9)$

Fig. 3-A

\section{CHP $0.06 \mathrm{M}, 22 \pm 1^{\circ} \mathrm{C}$}

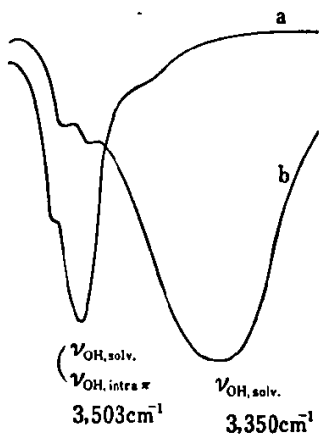

$350 \mathrm{~cm}^{-1}$
$\nu_{\mathrm{OH}}$, sssoc., under the condition whereby the product of hydroperoxide concentration and the length of light path are kept constant, clearly changes in accordence with the hydroperoxide concentration. That is to say, the intensity of

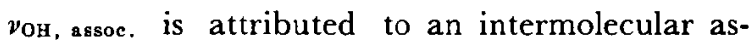
sociation of hydroperoxide. An absorption band of intramolecular H-bond ( $\left.\nu_{\mathrm{OH}}, \operatorname{lntra}_{*}\right)$ is observed between $\nu_{\mathrm{OH}}$, free and $\nu_{\mathrm{OH}}$, assoc. in the case of CHP (Fig. 2-B). The ratio of intensities of $\nu_{\mathrm{OH}}$, free and $\nu_{0 \mathrm{H} \text {, natra }}$, does not vary with hydroperoxide concentration and has a definite value according to the structure of aromatic HP, that is $44 / 56$ (BHP), 49/51 (EHP) and 55/45 (CHP). The absorption band of $\nu_{\mathrm{OH}}$, intra $\pi$ is characteristic for aromatic hydroperoxide and is assigned to intramolecular $\pi \mathrm{H}$-bond between the aromatic $\pi$ electron and perhydroxy hydrogen. $\mathrm{H}$-bonding absorption bands between hydroperoxide and solvent (benzene or dioxane) are shown in Fig. $3-\mathrm{A}$ and $3-\mathrm{B}$, and $v_{\mathrm{OH}}$, solv. is its wave number for maximum absorption.

The strength of the intra- and intermolecular $\mathrm{H}$-bond is evaluated relatively by the shift of frequency $(\Delta v)$ from $\nu_{\mathrm{OH}, \text { free. The data for each }}$ hydroperoxide are shown in Table 2. Suffix to $.1 v$ shows the type of association and the solvent solvated to the hydroperoxide. The $\nu_{\mathrm{OH}}$, free of each hydroperoxide appears within the range of $3,543 \sim 3,553 \mathrm{~cm}^{-1}$. The magnitude of the shift resulted from the intermolecular

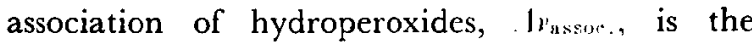
following order in aliphatic HP: prim. $<$ sec. $<$ tert. and the order is reversed in the case of aromatic hydroperoxides. Thus the following conclusion: the larger the value (absolute) of Taft's $\sigma^{*}$ notwithstanding the sing, the stronger the association. The intramolecular $\pi \mathrm{H}$-bond observed in the aromatic hydroperoxides is readily explained by the geometrical model shown in Fig. 4. When the plane containing three atoms $-\mathrm{O}-\mathrm{OH}$ is oriented perpendicular to the aromatic ring, the distance between the center of the aromatic ring and the terminal $\mathrm{H}$ atom is estimated to be $2.1 \sim 2.2 \AA$ and this well agrees with the $\mathrm{H}$-bonding distance. The shift, $1 \nu_{\text {intra } \pi}$, increases in the order of $\mathrm{BHP}<\mathrm{EHP}<\mathrm{CHP}$ and the acidity of hydroperoxide is in the opposite

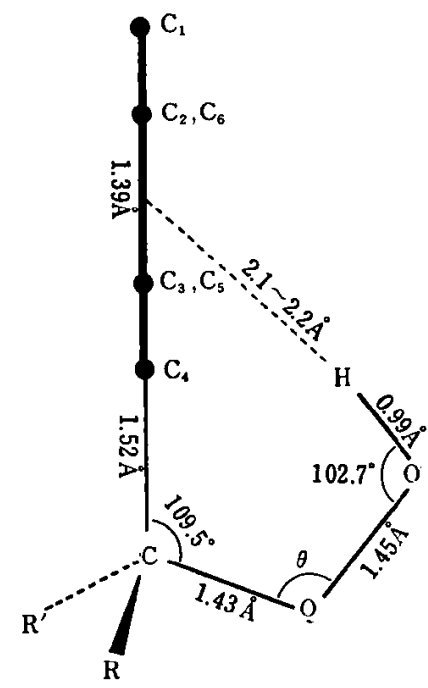

Fig. 4

Table 2 Shift of OH Vibration Frequency $\left(\mathrm{cm}^{-1}\right)$

Temp. $22 \pm 1^{\circ} \mathrm{C}$

\begin{tabular}{|c|c|c|c|c|c|c|c|c|}
\hline Solvent & Abs. Band & Shift & $n$-BuHP & $s e c-\mathrm{BuHP}$ & tert-BuHP & BHP & EHP & CHP \\
\hline $\begin{array}{c}\mathrm{CCl}_{4} \\
\text { Benzene + CC } \\
\text { 1-Octene + CC } \\
\text { Dioxane + CC } \\
0.036 \mathrm{M} \mathrm{TH}\end{array}$ & $\begin{array}{l}v_{\mathrm{OH}, \text { free }} \\
v_{\mathrm{OH}} \text { Intra } \pi \\
v_{\mathrm{OH}, \text { assoc. }} \\
(1: 1) \\
l_{4}(1: 1) v_{\mathrm{OH}}, \text { solv. } \\
(1: 9) \\
\mathrm{CCl}_{4}\end{array}$ & $\begin{array}{l}\Delta v_{\text {intra } \pi} \\
\left\{\begin{array}{l}\Delta v_{\text {assoc. }} \\
\Delta v_{\text {benzene }} \\
\Delta v_{1 \text {-octene }} \\
\Delta v_{\text {dioxane }} \\
\Delta v_{\text {THF }}\end{array}\right.\end{array}$ & $\begin{array}{r}3,548 \\
- \\
3,403 \\
145 \\
37 \\
64 \\
197 \\
241\end{array}$ & $\begin{array}{r}3,551 \\
- \\
3,398 \\
152 \\
37 \\
62 \\
192 \\
237\end{array}$ & $\begin{array}{r}3,553 \\
- \\
- \\
3,389 \\
164 \\
36 \\
59 \\
184 \\
229\end{array}$ & $\begin{array}{r}3,543 \\
3,528 \\
15 \\
3,415 \\
128 \\
47 \\
67 \\
210 \\
253\end{array}$ & $\begin{array}{r}3,544 \\
3,523 \\
21 \\
3,425 \\
119 \\
45 \\
63 \\
199 \\
247\end{array}$ & $\begin{array}{r}3,546 \\
3,518 \\
28 \\
3,432 \\
114 \\
43 \\
61 \\
196 \\
239\end{array}$ \\
\hline
\end{tabular}

* in the case, $[\mathrm{HP}]=0.6 \mathrm{M}$

Volume 12--May 1970 
order. This fact can be attributed to a change of bond angle at $\alpha$-carbon by a steric hindrance of its substituents.

The shift due to solvation, $1 h^{\prime}$ solr., increases with the basicity of solvent and the acidity of hydroperoxide.

\subsection{Association of Hydroperoxide}

Assocation of hydroperoxide in a dilute solution initially forms dimeric associate and a higher order aggregate is formed in a more concentrated solution as shown below.

$$
\begin{gathered}
2 \mathrm{ROOH} \stackrel{K \text { assoc. }}{\rightleftarrows}(\mathrm{ROOH})_{2} \\
(\mathrm{ROOH})_{a-1}+\mathrm{ROOH} \stackrel{K^{\prime} \text { assoc. }}{\rightleftarrows}(\mathrm{ROOH})_{n}
\end{gathered}
$$

Walling et al. ${ }^{13)}$ assumed the following cyclic associate as $\mathrm{H}$-bonding dimer constitution. In

$$
\mathrm{H} \cdot \mathrm{O}-\mathrm{O}
$$

the sufficiently dilute solution of HP, $K_{\text {assoc. }}$ is given by the Eq. 7, in which $P o$ is the total concentration of hydroperoxide and $P f$ is the concentration of unassociated hydroperoxide in equilibrium.

$$
K_{\mathrm{assoc}},=\left(P_{o}-P f\right) / 2 P f^{2}
$$

Pf can be calculated in terms of $E_{\mathrm{free}}$ (absorption intensity of $\nu_{\mathrm{OH}}$, free at $[\mathrm{HP}]_{1 \mathrm{im} \rightarrow \mathrm{o}}$ in the condition in which the product of hydroperoxide concentration and length of light path is constant). $K_{\mathrm{nssoc}}$. of aliphatic hydroperoxide is calculated by using Eq. 7 and shown in Table 3 .

In the case of aromatic HP, $K_{\text {assoc. was }}$ calculated by a similar treatment, taking the presence of intramolecular $\pi-\mathrm{H}$ bonding into consideration. The results are shown in Table 4. Calculated values of $K_{\text {assoc. }}$ in Table 3 and Table 4 reach asymptotically to a constant value as $P o$ decreases. The existence of higher order aggregate may be neglected approximately below $10^{-2}$ molar hydroperoxide concentration. Interpolated values of $K_{\mathrm{assoc}}$ to $[P o]_{11 \mathrm{~m} \rightarrow \mathrm{o}}\left(\right.$ real $\left.K_{\mathrm{assoc}}\right)$ are also shown in Table 5 .

\subsection{Effect of Hydroperoxide Structure on Olefin Epoxidation}

The epoxidation rates of 1 -octene were measured by using the six hydroperoxides in the presence of Mo catalyst, PMA or DEM.

The results are shown in Fig. 5 and the reaction conditions are shown in Fig. 5. Yields of epoxide are quantitative for the consumed hydroperoxide. Reaction rates are of the first order to [HP] and [Olefin] and the reaction rate constants, $k$, are calculated from the data. The reactivity of hydroperoxide for epoxidation is not much affected by its structure and does not coincide with its $\mathrm{pKa}$ value. The order of reactivity is tert. $<$ prim.<sec. in both series. As for catalysts, DEM

\begin{tabular}{|c|c|c|c|c|}
\hline$P o\left(\mathrm{~mol} \cdot l^{-1}\right)$ & $E_{\text {free }}$ & $P f \mid P o$ & $(P o-P f) / P o$ & $K_{\mathrm{assoc} .}\left(l \cdot \mathrm{mol}^{-1}\right)$ \\
\hline $\begin{array}{l}0.012 \\
0.024 \\
0.060 \\
0.120 \\
0.240 \\
0.600\end{array}$ & $\begin{array}{l}0.800 \\
0.763 \\
0.684 \\
0.597 \\
0.462 \\
0.275\end{array}$ & $\begin{array}{l}0.952 \\
0.908 \\
0.814 \\
0.710 \\
0.550 \\
0.327\end{array}$ & $\begin{array}{l}0.048 \\
0.092 \\
0.186 \\
0.290 \\
0.450 \\
0.673\end{array}$ & $\begin{array}{l}2.23 \\
2.35 \\
2.34 \\
2.39 \\
3.09 \\
5.24\end{array}$ \\
\hline sec-BuHP & \multicolumn{4}{|c|}{$\nu_{\mathrm{OH}, \text { free }} 3,551 \mathrm{~cm}^{-1}, E_{\mathrm{fre \theta}}^{\circ}=0.94$} \\
\hline $\begin{array}{l}0.012 \\
0.024 \\
0.060 \\
0.120 \\
0.240 \\
0.600\end{array}$ & $\begin{array}{l}0.889 \\
0.847 \\
0.752 \\
0.646 \\
0.484 \\
0.284\end{array}$ & $\begin{array}{l}0.946 \\
0.901 \\
0.800 \\
0.687 \\
0.515 \\
0.302\end{array}$ & $\begin{array}{l}0.054 \\
0.099 \\
0.200 \\
0.313 \\
0.485 \\
0.698\end{array}$ & $\begin{array}{l}2.53 \\
2.56 \\
2.61 \\
2.77 \\
3.80 \\
6.39\end{array}$ \\
\hline tert-BuHP & \multicolumn{4}{|c|}{$\nu_{\mathrm{OH}}$, free $3,553 \mathrm{~cm}^{-1}, E_{\mathrm{fre \theta}}^{\circ}=1.05$} \\
\hline $\begin{array}{l}0.012 \\
0.024 \\
0.060 \\
0.120 \\
0.240 \\
0.600\end{array}$ & $\begin{array}{l}0.991 \\
0.941 \\
0.832 \\
0.716 \\
0.527 \\
0.306\end{array}$ & $\begin{array}{l}0.943 \\
0.896 \\
0.792 \\
0.682 \\
0.502 \\
0.291\end{array}$ & $\begin{array}{l}0.057 \\
0.104 \\
0.208 \\
0.318 \\
0.498 \\
0.709\end{array}$ & $\begin{array}{l}2.66 \\
2.72 \\
2.76 \\
2.86 \\
4.12 \\
6.97\end{array}$ \\
\hline
\end{tabular}

Table 3 Calculation of Equilibrium Constant of Association of Aliphatic HP Solvent: $\mathrm{CCl}_{4} \quad \mathrm{C} \cdot 1=0.012 \quad$ Temp. $22 \pm 1^{\circ} \mathrm{C}$

$n$-BuHP $\quad \nu_{\mathrm{OH}}$, free $3,548 \mathrm{~cm}^{-1}, E_{\mathrm{free}}^{\circ}=0.84$ 
Table 4 Galculation of Equilibrium Constant of Association of Aromatic HP Solvent: $\mathrm{CCl}_{4} \quad \mathrm{C} \cdot 1=0.012$ Temp. $22 \pm 1^{\circ} \mathrm{C}$

BHP $v_{\mathrm{OH}, \text { free }} 3,543 \mathrm{~cm}^{-1}, E_{\text {iree }}^{\circ}=0.493$

\begin{tabular}{|c|c|c|c|c|c|}
\hline$P o\left(\mathrm{~mol} \cdot l^{-1}\right)$ & $E_{\text {free }}$ & $P f / P o$ & $P \pi / P o$ & $(P o-P f-P \pi) / P_{o}$ & $K_{\text {assoc. }}\left(l \cdot \mathrm{mol}^{-1}\right.$ \\
\hline $\begin{array}{l}0.012 \\
0.024 \\
0.060 \\
0.120 \\
0.240\end{array}$ & $\begin{array}{l}0.465 \\
0.442 \\
0.384 \\
0.328 \\
0.271\end{array}$ & $\begin{array}{l}0.416 \\
0.394 \\
0.343 \\
0.293 \\
0.242\end{array}$ & $\begin{array}{l}0.529 \\
0.502 \\
0.437 \\
0.372 \\
0.308\end{array}$ & $\begin{array}{l}0.056 \\
0.104 \\
0.220 \\
0.335 \\
0.450\end{array}$ & $\begin{array}{l}13.5 \\
13.9 \\
15.6 \\
16.3 \\
16.0\end{array}$ \\
\hline EHP & \multicolumn{5}{|c|}{$\nu_{\mathrm{OH}, \text { free }} 3,544 \mathrm{~cm}^{-1}, E_{\text {free }}^{\circ}=0.481$} \\
\hline $\begin{array}{l}0.012 \\
0.024 \\
0.060 \\
0.120 \\
0.240\end{array}$ & $\begin{array}{l}0.460 \\
0.442 \\
0.401 \\
0.356 \\
0.298\end{array}$ & $\begin{array}{l}0.469 \\
0.450 \\
0.408 \\
0.363 \\
0.303\end{array}$ & $\begin{array}{l}0.488 \\
0.468 \\
0.425 \\
0.378 \\
0.316\end{array}$ & $\begin{array}{l}0.044 \\
0 . c 82 \\
0.167 \\
0.259 \\
0.381\end{array}$ & $\begin{array}{l}8.32 \\
8.40 \\
8.39 \\
8.21 \\
8.64\end{array}$ \\
\hline CHP & \multicolumn{4}{|c|}{$v_{\mathrm{OH}, \text { free }} 3,546 \mathrm{~cm}^{-1}, E_{\mathrm{f} \text { ree }}^{\circ}=0.456$} & \\
\hline $\begin{array}{l}0.012 \\
0.024 \\
0.060 \\
0.120 \\
0.240\end{array}$ & $\begin{array}{l}0.441 \\
0.427 \\
0.392 \\
0.352 \\
0.300\end{array}$ & $\begin{array}{l}0.532 \\
0.515 \\
0.473 \\
0.425 \\
0.362\end{array}$ & $\begin{array}{l}0.435 \\
0.421 \\
0.387 \\
0.347 \\
0.296\end{array}$ & $\begin{array}{l}0.033 \\
0.064 \\
0.140 \\
0.228 \\
0.342\end{array}$ & $\begin{array}{l}4.85 \\
5.01 \\
5.23 \\
5.28 \\
5.45\end{array}$ \\
\hline
\end{tabular}

Table 5

\begin{tabular}{l|c|c|c|c|c|c}
\hline & $n$-BuHP & sec-BuHP & $t e r t$-BuHP & BHP & EHP & CHP \\
\hline $\begin{array}{l}K_{\text {assoc. }}\left(l \cdot \mathrm{mol}^{-1}\right) \\
K_{\text {intra } \pi}\end{array}$ & 2.28 & 2.52 & 2.65 & 13.1 & 8.32 & 4.81 \\
\hline
\end{tabular}

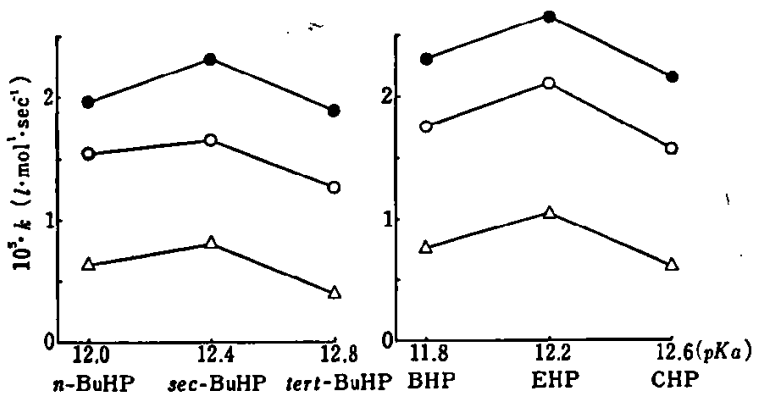

Rates of epoxidation with various hydroperoxides $\left(80^{\circ} \mathrm{C}\right)$

(olefin 1-octene: catalyst $4.95 \times 10^{-4} \mathrm{~mol} \cdot \mathrm{l}^{-1}$

$\{$ DEM-tert $-\mathrm{BuOH}$, O PMA-tert-BuOH,

$\triangle$ PMA-dioxane

Fig. 5-A

$5-B$

is more reactive than PMA, as the latter was made in aqueous solution and so that the hydration of HP or catalyst would take place to retard the epoxidation reaction. As for solvent, dioxane is more basic than tert-butanol and dioxane deactivates $H P$ by solvation. Generally speaking, solvation of hydroperoxide retards the formation of active complex which is formed from hydroperoxide and catalyst, thus strong donor-type solvents reduce considerably the rate of epoxidation. Consequently, Eq. 1 shown at the begin- ning of this paper should be rewritten as follows.

$$
\begin{aligned}
& \mathrm{ROOH}+\text { solvent } \stackrel{K_{\text {solv }}}{\rightleftarrows}(\mathrm{ROOH})_{\mathrm{sol} / \mathrm{v}} \\
& (\mathrm{ROOH})_{\text {solv }}+\text { catalyst } \stackrel{\stackrel{\kappa}{\rightleftarrows}}{\rightleftarrows}[\text { Complex] }+ \text { solvent }
\end{aligned}
$$

Sheng et al. ${ }^{4)}$ proposed I or II below for the structure of HP-catalyst-Olefin complex in the transition state of epoxidation. Giving attention to the fact that many of the active molybdenum catalysts have molybdenyl oxygen and considering the polar nature and bond distance of Mo-O, III seems the most reasonable structure, and it is well elucidated that peroxide (ROOR) does not act as an epoxidizing reagent.

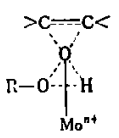

(I)

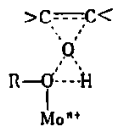

(I)

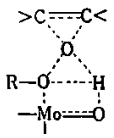

(II)
Various kinds of $\mathrm{H}$-bonding characteristics and pKa of hydroperoxide should have important effects on the bonding between catalyst and hydroperoxide, but these characteristics also govern the intermolecular association and solvation which retard complex formation. Consequently the characters of hydroperoxide do not 
correlate directly with the rate of epoxidation.

\section{Acknowledgements}

The authors wish to express their thanks to $\mathrm{Mr}$. Y. Tashiro and Mr. Y. Fujimoto for their assistance in the experimental work. This work was supported in part by a Grant in Aid of Scientific Research from the Ministry of Education.

\section{Literature}

1) Lee, J. B., Uff, B. O., Quart. Rev., 21, 429 (1967).

2) Brill, W. F., Indictor, N., J. Org. Chem., 29, 710 (1964).

3) Mashio, F., Kato, S., J. Syn. Org. Chem., Japan, 26, 367 (1968); Memoirs of Faculty of Kyoto Technical Univ., Science and Technology, 16, 79 (1967).

4) Sheng, M. N., Zajacek, J. G., "Oxidation of Organic Compounds", Vol. 2, pp. 418, (Adv. in Chem.,
Ser., 76) 1968 Am. Chem. Soc., Washington D. C. 5) Renolen, P., Ugelstad, J., J. Chem. Phys., 57, 634 (1960).

6) Huch, H., Ernst, F., Chem. Ber., 92, 2710 (1959); Walling, C., Bucker, S. A., J. Am. Chem. Soc., 77, 6032 (1955).

7) Crouthamel, C. E., Johnson, C. E., Anal. Chem., 26, 1284 (1954).

8) Gmelins Handbuch der Anorganischen Chemie. syst. No. 53, p. 173 (1938).

9) Albert, A., Serjeant, E. P., "Ionization Constants of Acid and Bases, A Laboratory Manual", Japanese Translation by Matsuura, pp. 63, (1963) Maruzen.

10) Everett, A. J., Minkoff, G. J., Trans. Faraday Soc., 49, 410 (1953).

11) Taft, Jr., R. W., J. Am. Chem. Soc., 74, 3120 (1952); 75, 4231 (1953).

12) Fox, J. J., Martin, A. E., Trans. Faraday Soc., 36, $897(1940)$.

13) Walling, C., Heaton, C. D., J. Am. Chem. Soc., 87, 48 (1965). 